\title{
Exposure to Occupational Health Hazards Among Nursing and Midwifery Students During Clinical Practice
}

Teka Gezehy Amare (iD)

Tizita Tariku Tesfaye ${ }^{2}$

Berhe Girmay ${ }^{3}$

Teklehaimanot Tesfay

Gebreagziabher (ID)

'Department of Nursing, College of Medicine and Health Science, Adigrat University, Adigrat, Ethiopia; ${ }^{2}$ Department of Nursing, College of Medicine and Health Science, Mettu University, Metu, Ethiopia; ${ }^{3}$ School of Nursing, College of Health Science,

Mekelle University, Mekelle, Ethiopia
Correspondence: Teka Gezehy Amare Tel +25I 9626I8557

Email tgzeaxum@gmail.com
Background: Health professionals are challenged with physical, chemical, and psychological hazards. The major areas in which nurses perform hazardous tasks were are injection, cleaning, patient care, bed making, cleaning and dressing of wounds, medication administration, and performing operations. During performing these activities, healthcare providers are exposed to many types of occupational hazards. So, there is a dearth of information on the prevalence of occupational hazards among nursing and midwifery students in this study area.

Objective: This study aims to assess exposure to occupational health hazards among nursing and midwifery students during clinical practice at Mekelle University.

Methods: Institutional-based cross-sectional study design was conducted from February to June 2017. The study participants were selected nursing and midwifery students of Mekelle University who had ever been attached for clinical practice. A sample of 151 students was recruited by a simple random sampling technique proportionate to their size. The data were collected using a self-administered questionnaire. The collected data were coded, entered, and cleaned by SPSS version 22 for analysis. Finally, the result was presented in the form of text, table, and figures.

Results: A total of 151 students had participated with a response rate of $100 \%$. The prevalence of psychosocial hazards, mechanical hazards, biological hazards, and physical hazards was 140 (92.7\%), 128 (84.8\%), 100 (66.2\%), and $100(66.2 \%)$, respectively. About $46(29.8 \%)$ had good knowledge, and $57(37.7 \%)$ of them had poor knowledge of the occupational hazard.

Conclusion and Recommendation: Psychosocial hazard was the most common occupational hazard among nursing and midwifery students. The majority of the students have poor knowledge concerning occupational hazards. To build a skilled nurse and midwife, it is mandatory to train all students before clinical practice about safe work practices and proper use of personal protective equipment.

Keywords: occupational hazard, nursing students, midwifery students, clinical practice

\section{Introduction}

Occupational hazards are defined as workplace issues that have likely to raise the hazard of our health, which can be categorized as biological and non-biological. Health professionals are challenges with physical, chemical, and psychological hazards. For example, moving the immobilized patients exposes workers to back injury and back pain. Moreover, during high workload and insufficient resources 
and equipment, healthcare professionals are faced with psychological hazards such as stress and depression. ${ }^{1-3}$

One of the commonest occupational hazards is a needlestick and sharp injury that occurs during commonly during nursing procedures like administering medications, administering or receiving blood, and performing other nursing activities containing sharp materials. The major causes of a needlestick and sharp injury are poor awareness of healthcare providers about the usage of sharp materials, its risks, and the prevention of a needlestick injury and proper waste disposal. Moreover, a needlestick injury also causes a burden for a patient if the injured healthcare providers carry hepatitis B or $\mathrm{C}$ and human immune deficiency virus. Nursing students are the most common healthcare professionals who face a needlestick and sharp injury in their work. ${ }^{4}$ A study done at Dammam University revealed that greater than $75 \%$ of the nursing students had no prior training about physical occupational hazards. ${ }^{5}$ People living in low-income countries rank the highest magnitude of human immune deficiency viruspositive patients worldwide and show the peak incidences of exposures to occupational hazards. ${ }^{6}$

The major areas in which nurses perform hazardous tasks were injection, cleaning, patient care, bed making, cleaning and dressing of wounds, medication administration, and performing operations. During performing these activities, healthcare providers are exposed to many types of hazards including physical, chemical, mechanical, and biological hazards. ${ }^{7}$ During clinical practice, Nursing and Midwifery students are exposing to occupational hazards during performing skills such as assisting and delivering baby, administering, and handling various types of fluids and medications, and many nursing skills including wound dressing. ${ }^{8}$

In Ethiopia, there are only a few studies that showed occupational hazard among nursing and midwifery students. Moreover, the burden of exposure to occupational hazards among Nursing and Midwifery students was not broadly determined yet. Besides, there is a dearth of information on the prevalence of occupational hazards among Nursing and Midwifery students in this study area. Therefore, this study aims to assess exposure to occupational hazards among Nursing and Midwifery students at Mekelle University, Northern Ethiopia. This study helps to Nursing and Midwifery students working in clinical practice, policymakers, and non-governmental organizations in refocusing their approach in planning and early intervention of occupational hazards to students during clinical practice to decrease the burden of occupational hazards.

\section{Methods and Materials}

\section{The Study Design, Setting, and Period}

This institution-based cross-sectional study was conducted at Mekelle University, Northern Ethiopia from February to June 2017 which is $780 \mathrm{~km}$ North of Addis Ababa. Mekelle University College of health sciences is founded in Ayder comprehensive, specialized referral hospital, which is a referral and teaching governmental hospital under the ministry of health. It has 500 inpatient beds in four major departments and other specialty units. The total number of nursing and midwifery students was 219 according to a 2017 report.

\section{Study Participants}

Selected Nursing and Midwifery students who had started clinical practice and available during the data collection time were included in the study. But, severely ill individuals at the time of data collection were excluded from the study.

\section{Sampling Size Determination}

The sample size was determined by a formula for estimating a single population proportion; using the prevalence of occupational hazard among nursing and midwifery students, 60.9\% from a study done in Addis $\mathrm{Ababa}^{9}$ and marginal error 5\% (assuming 95\% confidence interval) and the sample size for the study was 366 . Since the calculated sample is more than the study population, a correction formula was used. The initial calculated sample size was 366 , but the study population was 219 . Therefore, we apply a correction formula. The formula was $\mathrm{nf}=\mathrm{ni} \times \mathrm{N} \div \mathrm{ni}+\mathrm{N}=(366 \times 219) \div(366$ $+219)=137$. Where $\mathrm{nf}=$ desired sample size, $\mathrm{ni}=$ calculated sample size (366), and $\mathrm{N}=$ total number of nursing and midwifery students who are the second year and above (219). Finally, by Adding $10 \%$ of non-response rate the final total number of nursing and midwifery students was 151 .

\section{Sampling Method and Sampling Procedure}

A simple random sampling method was employed to select the intended study subjects from second, third, and fourthyear nursing and midwifery students in each section proportionally independently of their size. A list of students 
was collected from both departments and then the selection of 151 students was performed using by lottery method. After proportionate allocation to each department and class, we randomly selected the required sample size from each class by the given sampling frame. For example, to select study subjects from second-year nursing students, the sampling frame for the second year was 46 . So, to select 32 study participants we randomly select 32 students out of 46 students by lottery method. We performed the random sampling method in the same manner for all study participants (Figure 1).

\section{Data Collection Tool and Technique}

The data were collected using a structured self-administered questionnaire adapted from literature. ${ }^{9}$ Initially, we got permission from the online service of Addis Ababa University, and then we modified the questionnaire. The questionnaires had prepared with socio-demographic characteristics like age, religion, sex, educational level, area of clinical practice covered, ethnicity, marital status, department, knowledge on the occupational hazard and its sources, psychosocial hazards like stress, physical hazards like material, slippery floor, mechanical hazards like a needle prick, and biological hazards like blood splash. The validity and reliability of the questionnaire were checked (Appendix).

\section{Measurement Exposure to Occupational Hazards}

Defined as having at least one of physical, mechanical, biological, and psychosocial harm, in the area of Nurse and Midwife students' clinical practice.

\section{Knowledge}

(Good: those students who scored greater than or equal to $70 \%$ on the causes of occupational health hazards, fair: those students who scored $60-69 \%$ and poor those students who scored less than $60 \%){ }^{10}$

\section{Severely III Individuals}

Means students who go to a clinic or hospital follow-up during clinical practice for the reason of having abdominal cramp-like appendicitis, severe peptic ulcer disease, and diseases induced severe pain like pain after exposure to occupational hazards (needlestick injuries, accidental fall from floor, etc.).

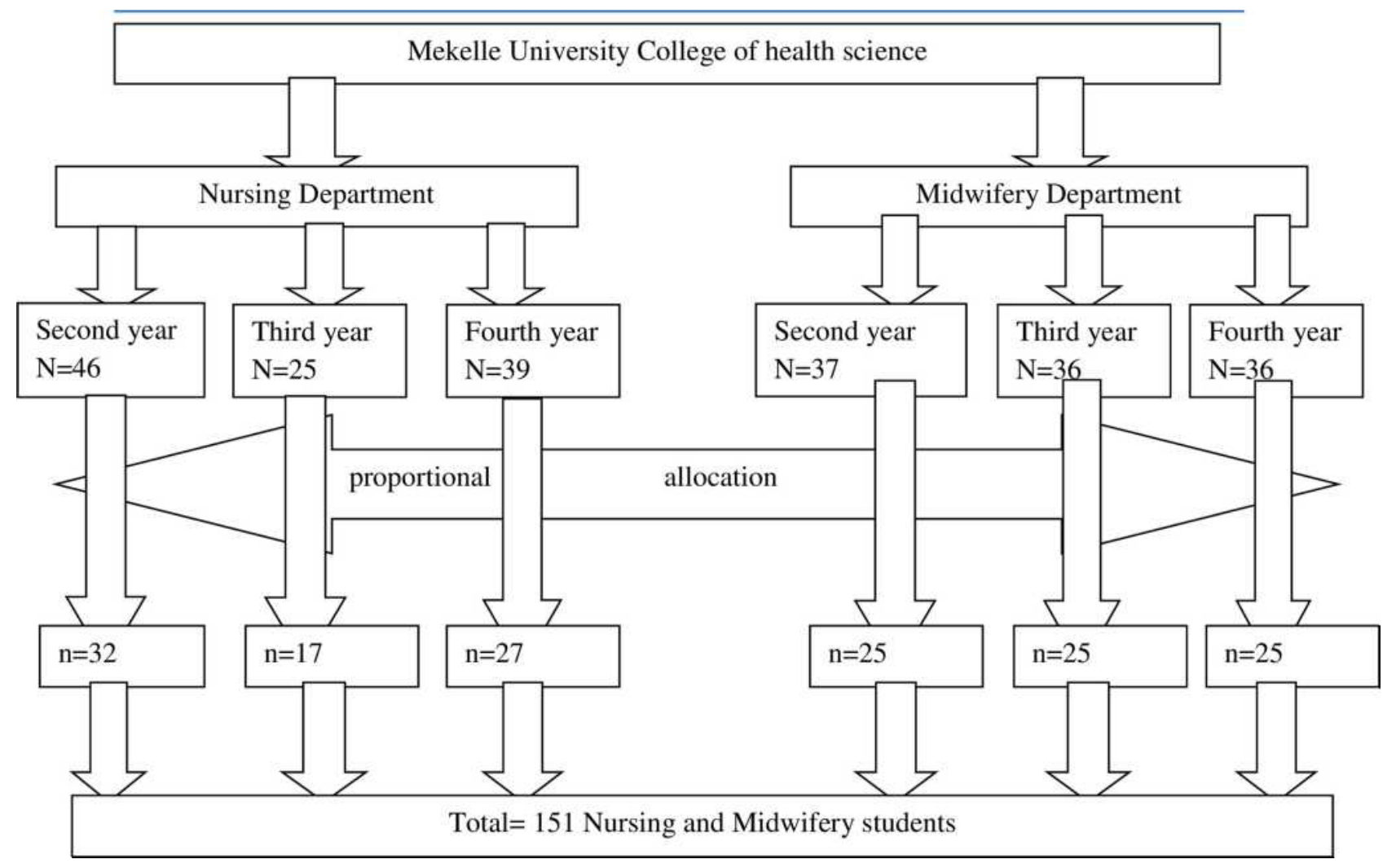

Figure I Schematic representation of sampling procedures in Mekelle University nursing and midwifery students, 2017. 


\section{Data Quality Assurance}

Before data collection, one-day training was given for data collectors. A pre-test was done in $10 \%$ of the sample size at Adigrat University. Frequent supervision and monitoring of all activities of the study was done during the data collection process. At the end of each data collection day, the principal investigator had checked the completeness of questionnaires and the quality of the recorded information. The questionnaire was prepared in the English version.

\section{Data Processing and Analysis}

After data collection, the response was coded and entered into a computer using SPSS version 22 to process and analyze the data. Data were calculated using the frequency and percentage. The data were presented in texts, tables, and figures.

\section{Ethical Consideration}

This study was approved by the Institutional Review Board of Mekelle University, College of health sciences directorate office with the code number of ERC 1267/ 2017. All participants were informed about the purpose of the study, and that it was conducted in accordance with the Declaration of Helsinki. Written informed consent was taken from each respondent to obtain their agreement. Participants were informed that; the right to refuse or discontinue participating in the research without any compromise in the service. No potential risk had been expected for the study participants.

\section{Result}

\section{Socio-Demographic Characteristics of the Study Participants}

A total of 151 study participants who fulfilled the inclusion criteria were included in the study with a response rate of $100 \%$. Seventy-six (50.3\%) of them were nursing students. Also, 57 (37.7\%) of the study population were second-year students. Based on our result, more than half of the respondents $80(53 \%)$ were females. The mean age of the students was 22.7, with a standard deviation of 1.625. Also, over half of the respondents 82 (54.3\%) belonged to Tigray and the religious background shows many of the students $128(84.8 \%)$ were orthodox (Table 1).

\section{Knowledge of Study Participants on Occupational Hazard}

Most of the respondent's 87 (57.6\%) said that they know needle prick, blood flash, and skin cut can cause an occupational hazard. Majority (80 (53\%)) had mixed (mass media, nursing school, journal, and books) sources of information about occupational hazards. Regarding the knowledge of occupational hazards in the clinical area as a whole 46 (29.8\%) had good knowledge and 57 (37.7\%) of them had poor knowledge (Table 2).

\section{Biological Hazards Among Nursing and Midwifery Students}

Regarding biological hazards, about 30 (19.9\%) had got blood splash sometimes and $21(13.9 \%)$ have got blood splash occasionally. About $37(24.5 \%)$ of the students stated that they became sick during clinical practice. The diagnosis of their sickness clarified that many of the respondents $26(65 \%)$ were diagnosed as typhoid. The prevalence of biological hazards among nursing and midwifery students was 100 (66.2\%) (Table 3).

\section{Physical Hazards Among Nursing and Midwifery Students}

Out of the total students who participated in this study, only $14(9.3 \%)$ students respond that they faced fall due to the slippery floor and $56(37.1 \%)$ faced physical hazards due to loud noise. Eighty (53\%) of the sampled students respond that there was a shortage of material while they were giving care in the health institution where they have been assigned. About 60 (39.7\%) of the students faced occupational hazards during clinical practice due to poor lightening. The prevalence of physical hazards among nursing and midwifery students was $100 \quad(66.2 \%)$ (Table 4).

\section{Mechanical Hazards Among Nursing and Midwifery Students}

About 57 (37.7\%) of the students had been exposed to needle prick always, often, sometimes, and occasionally. The measure they took after biomechanical injury was the use of antiseptic solution by 55 (36.4\%) students and wash hands with soap and water by $40(26.5 \%)$ students. Most of the students 127 (84.1\%) reported that they did not get scalpel cut. About 87 (57.6\%) of the respondents were got back pain during clinical practice. The majority of the 
Table I Socio-Demographic Characteristics of Study Participants in Mekelle University, Northern Ethiopia, 2017 (N=I5I)

\begin{tabular}{|c|c|c|c|}
\hline Variables & Characteristics & Frequency & Percent \\
\hline \multirow[t]{2}{*}{ Sex } & Female & 80 & 53.0 \\
\hline & Male & 71 & 47.0 \\
\hline \multirow[t]{2}{*}{ Age in years } & $20-23$ & 104 & 68.9 \\
\hline & $24-27$ & 47 & 31.1 \\
\hline \multirow[t]{2}{*}{ Department } & Nursing & 76 & 50.3 \\
\hline & Midwifery & 75 & 49.7 \\
\hline \multirow[t]{3}{*}{ Academic rank } & Second year & 57 & 37.7 \\
\hline & Third year & 42 & 27.8 \\
\hline & Fourth year & 52 & 34.4 \\
\hline \multirow[t]{4}{*}{ Area of clinical practice covered } & Pediatrics, medical, surgical and orthopedic & 23 & 15.2 \\
\hline & Medical, surgical and orthopedic ward & 74 & 49.0 \\
\hline & All & 48 & 31.8 \\
\hline & Others* & 6 & 4.0 \\
\hline \multirow[t]{2}{*}{ Marital status } & Single & 140 & 92.7 \\
\hline & Married & 11 & 7.3 \\
\hline \multirow[t]{5}{*}{ Ethnicity } & Tigray & 82 & 54.3 \\
\hline & Amhara & 46 & 30.5 \\
\hline & Oromo & 13 & 8.6 \\
\hline & SNNPR & 4 & 2.6 \\
\hline & Others** & 6 & 4.0 \\
\hline \multirow[t]{4}{*}{ Religion } & Orthodox & 128 & 84.8 \\
\hline & Muslim & 12 & 7.9 \\
\hline & Protestant & 7 & 4.6 \\
\hline & Others*** & 4 & 2.6 \\
\hline
\end{tabular}

Notes: *Refers to obstetrics and gynecology, intensive care unit, emergency; ** refers to Afar, Sudan; others*** refers to Catholic and Adventist.

Table 2 Knowledge of Nursing and Midwifery Students on Occupational Hazards in Mekelle University, Northern Ethiopia, 2017 $(\mathrm{N}=15 \mathrm{I})$

\begin{tabular}{|c|c|c|c|}
\hline Variables & Characteristics & Frequency & Percent \\
\hline \multirow[t]{2}{*}{ Have you learned about occupational hazards in nursing or midwifery school? } & Yes & 146 & 96.7 \\
\hline & No & 5 & 3.3 \\
\hline \multirow[t]{2}{*}{ Do you know needle prick, blood flush, skin cut can cause an occupational hazard } & Yes & 87 & 57.6 \\
\hline & No & 84 & 42.4 \\
\hline \multirow[t]{2}{*}{ Do you know mechanical injuries; chemical, biological factors can cause an occupational hazard? } & Yes & 108 & 71.5 \\
\hline & No & 43 & 28.5 \\
\hline \multirow[t]{3}{*}{ Sources of information on occupational hazards } & School & 65 & 43 \\
\hline & Mixed & 80 & 53 \\
\hline & Others & 6 & 4 \\
\hline \multirow[t]{3}{*}{ Knowledge of occupational hazards in the clinical area } & Good & 46 & 29.8 \\
\hline & Fair & 49 & 32.5 \\
\hline & Poor & 57 & 37.7 \\
\hline
\end{tabular}


Table 3 Biological Hazards Among Nurses and Midwifery Students in Mekelle University, Northern Ethiopia, 2017 (N=I5I)

\begin{tabular}{|c|c|c|c|}
\hline Variables & Characteristics & Frequency & Percent \\
\hline \multirow[t]{3}{*}{ How many times students had blood splash during clinical practice } & Some times & 30 & 19.9 \\
\hline & Occasionally & 21 & 13.9 \\
\hline & Not at all & 100 & 66.2 \\
\hline \multirow[t]{2}{*}{ Students become sick during clinical practice } & Yes & 37 & 24.5 \\
\hline & No & 114 & 75.5 \\
\hline \multirow[t]{4}{*}{ Diagnosis of students who become sick during clinical practice } & TB & 2 & 5 \\
\hline & Typhoid & 27 & 67.5 \\
\hline & Hepatitis & 6 & 15 \\
\hline & Others* & 5 & 12.5 \\
\hline
\end{tabular}

Notes: $\mathrm{s}^{*}$ Refers to tonsillitis, PUD and common cold.

Table 4 Physical Hazards Among Nurse and Midwife Students in Mekelle University, Northern Ethiopia, 2017 (N=I5I)

\begin{tabular}{|l|l|l|l|}
\hline Variables & Characteristics & Frequency (N=I5I) & Percent \\
\hline Students face falling accident in clinical practice due to slippery floor & Yes & 14 & 9.3 \\
& No & 137 & 90.7 \\
\hline Students come across an electrical accident in clinical practice & $\begin{array}{l}\text { Yes } \\
\text { No }\end{array}$ & 4 & 147 \\
\hline Students have faced problem due to loud noise in clinical practice & Yes & 56 & 9.6 \\
& No & 95 & 37.1 \\
\hline Students faced occupational hazard during clinical practice due to poor lightening & Yes & 60 & 62.9 \\
\hline
\end{tabular}

Table 5 Mechanical Hazards Among Nurses and Midwife Students in Mekelle University, Northern Ethiopia, 2017 (N=I5I)

\begin{tabular}{|c|c|c|c|}
\hline Variables & Characteristics & Frequency & Percent \\
\hline \multirow[t]{5}{*}{ Frequency of students needle prick during clinical practice } & Always & 5 & 3.3 \\
\hline & Often & 5 & 3.3 \\
\hline & Sometimes & 19 & 12.6 \\
\hline & Occasionally & 28 & 18.5 \\
\hline & Never & 94 & 62.3 \\
\hline \multirow[t]{4}{*}{ Measures taken while students accidentally got needle prick } & Report to the counselor & 33 & 21.9 \\
\hline & Wash soap and water & 40 & 26.5 \\
\hline & Use antiseptic solution & 55 & 36.4 \\
\hline & No any measures taken & 23 & 15.2 \\
\hline \multirow[t]{2}{*}{ Students have scalpel cutting during performing procedure } & Yes & 24 & 15.9 \\
\hline & No & 127 & 84.1 \\
\hline \multirow[t]{2}{*}{ Students have cut from drug ampoules during clinical practice } & Yes & 46 & 30.5 \\
\hline & No & 106 & 69.5 \\
\hline \multirow[t]{2}{*}{ Back pain during clinical practice } & Yes & 87 & 57.6 \\
\hline & No & 64 & 42.4 \\
\hline \multirow[t]{3}{*}{ Reason for having back pain } & Wound dressing & 42 & 47.2 \\
\hline & Prolong standing & 23 & 25.8 \\
\hline & Mixed causes & 24 & 27 \\
\hline
\end{tabular}


Table 6 Psychosocial Hazards Among Nurse and Midwife Students in Mekelle University, Northern Ethiopia, 2017 (N=15I)

\begin{tabular}{|l|l|l|l|}
\hline Variables & Characteristics & Frequency & Percent \\
\hline Fear of occupational hazards & Yes & 98 & 64.9 \\
& No & 53 & 35.1 \\
\hline Reasons for fear & $\begin{array}{l}\text { Death of patients } \\
\text { Risk of infection }\end{array}$ & 121 & 19 \\
\hline Students take drugs without prescription & Yes & 54 & 86.4 \\
& No & 97 & 35.8 \\
\hline Students have fear to give care for HIVIAIDS, TB, and hepatitis patients & Yes & 126 & 64.2 \\
& No & 25 & 83.4 \\
\hline
\end{tabular}

reason provided for having back pain was $42(47.2 \%)$ wound dressing. The overall prevalence of biomechanical hazards among nursing and midwifery students was 128 (84.8\%) (Table 5).

\section{Psychosocial Hazards Among Nursing and Midwifery Students}

The majority (64.9\%) of the participants had fear of occupational hazards while giving care to clients. Our study indicates that the majority of the participants 121 (80.1\%) responded that they did worry due to the death of patients. Moreover, the majority (83.4\%) of the Students had feared to give care for human immune deficiency virus, tuberculosis, and hepatitis patients. About 54 (35.8\%) of the participants were ever taking drugs without prescription of health professionals. The Overall prevalence of psychosocial hazards among nursing and midwifery students was 140 (92.7\%) (Table 6).

\section{The Magnitude of Exposure to Occupational Hazards}

The overall magnitude biological hazard, physical hazard, mechanical hazard, and psychological hazard were $66.2 \%$, $66.2 \%, 84.8 \%$, and $92.7 \%$, respectively. Of the exposed students $77(53.5 \%)$ of them were females. The occupational hazard based on their educational level was 56 (38.9\%), $38(26.4 \%)$, and $50(34.7 \%)$ for second year, third year, and fourth year, respectively (Figure 2).

\section{Discussion}

The overall magnitude biological hazard, physical hazard, mechanical hazard, and psychological hazard were $66.2 \%$,

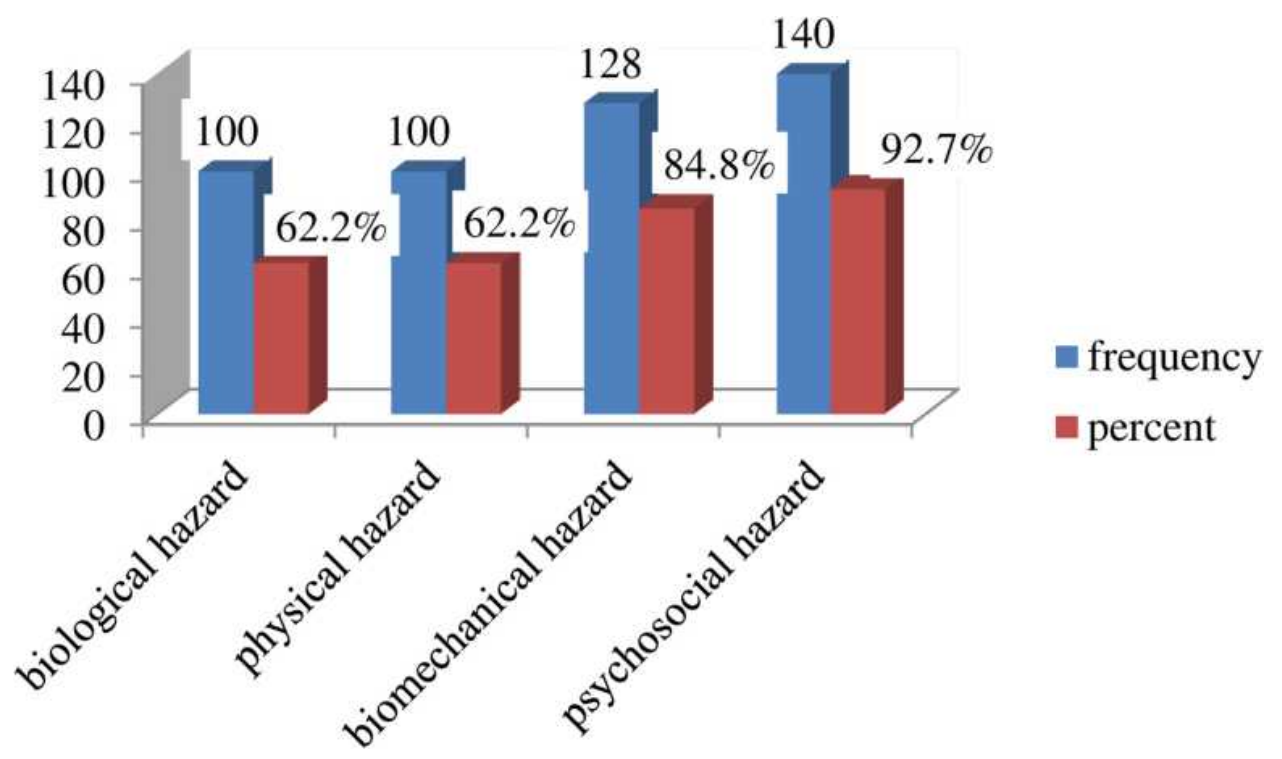

Figure 2 Magnitude of occupational hazards among nursing and midwifery students at Mekelle University, Northern Ethiopia, 2017 (N=I5I). 
$66.2 \%, 84.8 \%$, and $92.7 \%$, respectively. This study is different from a study done by Zagazig University in Egypt in which biological hazard, physical hazard, mechanical hazard, and psychological hazard accounts about $10.48 \%$, $74.89 \%, 51.31 \%$, and $88.4 \%$, respectively. ${ }^{11}$ This difference could be due to the variation of inadequate knowledge and skills about occupational health hazards, safety measures, and personal protective equipment, especially before their first field practice.

According to this study, the overall knowledge having good knowledge, fair knowledge and poor knowledge about occupational hazards at the clinical practice was $29.8 \%, 32.5 \%$, and $37.7 \%$, respectively. This is different from a study done in Addis Ababa in which 45.3\% had good knowledge, $35.3 \%$ had fair knowledge, 15.4\%) had poor knowledge 9 and Nigerian teaching hospital, in which $37.1 \%$ had good knowledge, $19.4 \%$ had fair knowledge, and $43.5 \%$ of them had poor knowledge, on occupational hazards. ${ }^{12}$ This difference may be due to their interest in the profession, and the difference in the study period.

According to the result of this study, $64.9 \%$ of the students had fear of occupational hazards. This is almost similar in percentage with the result of the research done at the University of Benin Teaching Hospital in Nigeria, where $62.3 \%$ of the study participants were fearful. ${ }^{13}$ This similarity may be associated with similarity in the educational level of students and minimal exposure of students to the practice area. However, this study is different from a study done in Turkey $(21.5 \%),{ }^{14}$ and Addis Ababa $(29.4 \%)^{9}$ had fear of occupational hazard. This difference may be due to students in Addis Ababa may take a train about the standard precaution techniques to prevent occupational health hazards and psychological preparation before clinical practice.

Regarding the physical factors of occupational hazards among nursing and midwifery students at Mekelle University, $53 \%$ of the study participants reported that there was a shortage of materials in health institutions during clinical practice. This has a great difference from the result of a study done in Addis Ababa in which the majority $92.7 \%$ confirmed that there was a shortage of materials in health institutions during clinical. ${ }^{9}$ This difference may be due to the repeated overload of the health institutions they are attached with a great number of students and the improved supply of equipment to health institutions at a current time relative to the past.

In this study, $9.3 \%$ of the study participants had faced accidental falls due to the slippery floor. This is similar to a study done at Addis Ababa (9.7\%) of the study participants who faced accidental falls due to the slippery floor. ${ }^{9}$ This similarity may be related to almost similar designs of the Ethiopian health institutions.

This study result indicated that $37.7 \%$ of the participants got a needlestick injuries always, sometimes, and occasionally. This similar to a study done in Addis Ababa (38.2\%) of the participants got needle prick ${ }^{9}$ and a study done in Hamadan University of Iran (38\%) had experienced a needlestick injury. ${ }^{15}$ This similarity could be due to a similar level of students' educational level and knowledge about sharp equipment in the clinical area. But, it is lower than the study conducted in Haramaya and Jigjiga University, ${ }^{16}$ subSaharan Africa, ${ }^{17}$ Turkey, ${ }^{18}$ South Jordan, ${ }^{19}$ Southern Taiwan, $^{20}$ India, $^{21}$ and China ${ }^{22}$ in which $62.8 \%, 57 \%$, $50.8 \%, 46 \%, 50.1 \%, 76.4 \%$, and $76.6 \%$ had needlestick injury, respectively. This difference may be due to a lack of adequate personal protective equipment's lack of awareness and practice about the standard precautions. ${ }^{16}$

In this study, $57.6 \%$ had got back pain. This finding similar to a study done at Addis Ababa (60.9\%) ${ }^{9}$ and Turkey $(61.4 \%){ }^{23}$ This similarity may be due to similar patient load in the sites and the students' frequent patient nursing care activity involvements. But, it is lower than a study done in Nigeria $(88.5 \%)^{13}$ and it is higher than the study done in Turkey $(2.84 \%)^{24}$ and Korea (39.1\%). ${ }^{25}$ This difference may be due to variation in the study setting and low ratio of nurse-patient, which decreases workload.

\section{Strength and Limitation of the Study}

The strength of the study was the instrument used to collect data was structured and pre-tested on similar populations. The limitations of the study were the study was prone to recall bias due to being self-reporting and the nature of the study design.

\section{Conclusion}

According to this study nursing and midwifery students are at high risk of occupational hazards due to psychological, biological, physical hazard, and mechanical hazards. Psychosocial hazard is the most common occupational hazard among nursing and midwifery students during clinical practice. This study showed that the majority of the Nurses and Midwifery students have poor knowledge concerning occupational hazards at the clinical practice. The majority of the students have a feeling of stress from fear 
of occupational hazards while caring for a patient. The shortage of materials in the clinical area was also raised as the main problem by around half of the study participants.

\section{Implication and Impact of This Study}

Previously no study provides information about exposure to occupational hazards among nursing and midwifery students at Mekelle University and students were exposed to many risks. This study shows there is a high rate of occupational hazards among nursing and midwifery students. The results of the study will help the students, instructors, the health institution where students are practiced to aware of the risk factors of occupational hazards and to prepare manuals that guide their students to prevent the problem. It will also important to prepare guidelines about effective handling and usage of sharp materials, proper donning, and doffing of personal protective equipment with cooperating the health professional working in the health institutions. Finally, this study implies a baseline data for curriculum designers and policymakers working in health hazard aspects.

\section{Public Health Impact or Recommendation of This Study}

Even though most of the occupational hazard problems are manageable by the students themselves, the researcher believes the following intervention should be done in the future. One, the nursing and midwifery schools as well as clinical area coordinators and students should work with co-operation. Second, the study confirms that there is a high magnitude of psychological hazard; therefore, health education and awareness creation should be done before starting clinical practice. Third, we recommend to nursing and midwifery schools to prepare adequate personal equipment during clinical practice and the students should strictly follow the universal precautions. Fourth, to prevent the occupational health hazard risks it is better to create a counseling office that gives awareness creation about the mechanism to reduce occupational hazards and services for psychological hazards. Finally, we recommend a follow-up study to researchers working in occupational health and safety by considering this data as a baseline.

\section{Data Sharing Statement}

The data sets used and/or analyzed during the current study can be available from the corresponding author on reasonable request.

\section{Acknowledgments}

The authors are grateful to Mekelle University, School of Nursing for giving us this chance. We would also like to extend our gratitude to data collectors and study participants for their cooperation in providing the required information.

\section{Author Contributions}

All authors made a significant contribution to the work reported, whether that is in the conception, study design, execution, acquisition of data, analysis, and interpretation, or in all these areas; took part in drafting, revising, or critically reviewing the article; gave final approval of the version to be published; have agreed on the journal to which the article has been submitted; and agree to be accountable for all aspects of the work.

\section{Funding}

There is no funding to report.

\section{Disclosure}

The authors report no conflicts of interest in this work.

\section{References}

1. Ghana Ministry of Health. Occupational Health and Safety Policy and Guidelines for the Health Sector. Ghana: Ministry of Health/Ghana Health Service; 2010:68. Available from: http://www.moh-ghana.org/ UploadFiles/Publications/OHS\%20Policy\%20\&\%20Giudelines\% 20for\%20Health\%20Sector140204090745.pdf. Accessed 3 July 2020.

2. Bazeyo W, Buregyeya E, Halage A, et al. Occupational health hazards among healthcare workers in Kampala, Uganda. J Environ Public Health. 2015;2015:9. doi:10.1155/2015/913741:9

3. Huang HYQ, Tang S, An R:. Occupational exposure among Chinese nursing students: current status, risking factors and preventive interventions. Int J Clin Exp Med. 2016;9(8):16578-16586.

4. Trivedi A, Kasar PK, Tiwari R, Verma P, Sharma A. An educational interventional programme for prevention and management of needle stick injuries among nursing students at a tertiary care hospital, Jabalpur, Madhya Pradesh. Natl J Community Med. 2013;4(1):132136.

5. Abd El-Hay S. Prevention of needle stick and sharp injuries during clinical training among undergraduate nursing students: effect of educational program. IOSR J Nurs Health Sci. 2015;4(4):19-32.

6. Hutin Y, Hauri A, Chiarello L, et al. Best infection control practices for intradermal, subcutaneous, and intramuscular needle injections. Bull World Health Organ. 2003;81:491-500.

7. Manyele S, Ngonyani H, Eliakimu E. The status of occupational safety among health service providers in hospitals in Tanzania. Tanzan $J$ Health Res. 2008;10(3):159-165. doi:10.4314/thrb.v10i3.14356

8. Atulomah N, Oladepo O. Knowledge, perception and practise with regards to occupational risks of HIV/AIDS among nursing and midwifery students in Ibadan, Nigeria. Afr J Med Med Sci. 2002;31 (3):223-227.

9. Fite T. Assessment of Occupational Hazards Among Students of Nursing and Midwifery in Clinical Practice, in Addis Ababa, Ethiopia, 2009. Addis Ababa University; 2009. 
10. Karim MA, Ahmed SM, Qadir KJ, Nasrabadi AN. Assessment of nurses' knowledge regarding needle prick injury in Erbil Hospitals. Kufa J Nurs Sci. 2015;5(1):207-212.

11. Nabil NM, Sorour AS, Ahmed FM. Occupational health hazards among faculty of nursing students in Zagazig University. Zagazig Nurs J. 2018;14(1):133-147.

12. Ofili S. Knowledge and practice of universal precautions among student nurses at a Nigerian teaching hospital. Afr $J$ Nurs Midwifery. 2003;5(2):39-43.

13. Ofili S. Occupational hazards among student nurses at the University of Benin Teaching Hospital, Benin City, Edo-State, Nigeria. Afr $J$ Nurs Midwifery. 2002;4(1):15-19.

14. Çelebioğlu A, Akpinar RB, Küçükoğlu S, Engin R. Violence experienced by Turkish nursing students in clinical settings: their emotions and behaviors. Nurse Educ Today. 2010;30(7):687-691. doi:10.1016/ j.nedt.2010.01.006

15. Amini R, Soltanian AR, Ebrahimkhani A, Beigyan M. Investigating the use of safe injection guidelines after needle stick and sharp instruments injuries in nursing \& midwifery students of Hamadan University of Iran. $J$ Med Res. 2016;5(1):8-14.

16. Yeshitila M, Mengistie B, Demessie A, Godana W. Prevalence and associated factors of needle stick injury among nursing and midwifery students an Haramaya and Jigjiga University, Eastern Ethiopia. Prim Health Care. 2015;5(1):1-6.

17. Nsubuga FM, Jaakkola MS. Needle stick injuries among nurses in sub-Saharan Africa. Trop Med Int Health. 2005;10(8):773-781. doi:10.1111/j.1365-3156.2005.01453.x
18. Talas MS, Kocaöz S. Occupational needlestick-sharp injuries during clinical practice training and status of hepatitis B immunization in nursing and midwifery students. Turk J Rese Dev Nurs. 2015;17.

19. Nawafleh HA, El Abozead S, Al Momani MM, Aaraj H. Investigating needle stick injuries: incidence, knowledge and perception among South Jordanian nursing students. J Nurs Educ Pract. 2017;8(4):59-69. doi:10.5430/jnep.v8n4p59

20. Yang Y-H, Wu M-T, Ho C-K, et al. Needlestick/sharps injuries among vocational school nursing students in southern Taiwan. Am J Infect Control. 2004;32(8):431-435. doi:10.1016/j.ajic.2004.02.007

21. Hussain J, Ram SM, Galinde J, Jingade R. Occupational exposure to sharp instrument injuries among dental, medical and nursing students in Mahatma Gandhi Mission's Campus, Navi Mumbai, India. $J$ Contemp Dent. 2012;2(2):1-10. doi:10.5005/jp-journals-10031-1001

22. Cheung K, Ching SSY, Chang KKP, Ho SC. Prevalence of and risk factors for needlestick and sharps injuries among nursing students in Hong Kong. Am J Infect Control. 2012;40(10):997-1001. doi:10.1016/j.ajic.2012.01.023

23. Eyi S, Eyi İ. Nursing students' occupational health and safety problems in surgical clinical practice. SAGE Open. 2020;10 (1):2158244020901801. doi:10.1177/2158244020901801

24. Besey Ö, Zengin N. Assessing health threatening problems among nursing or midwifery students during the clinical education course in Turkey. Iran J Public Health. 2019;48(1):85.

25. Smith DR, Choe M-A, Chae YR, Jeong J-S, Jeon MY, An GJ. Musculoskeletal symptoms among Korean nursing students. Contemp Nurse. 2005;19(1-2):151-160. doi:10.5172/conu.19.1-2.151
Risk Management and Healthcare Policy

\section{Publish your work in this journal}

Risk Management and Healthcare Policy is an international, peerreviewed, open access journal focusing on all aspects of public health, policy, and preventative measures to promote good health and improve morbidity and mortality in the population. The journal welcomes submitted papers covering original research, basic science, clinical \& epidemiological studies, reviews and evaluations,

\section{Dovepress}

guidelines, expert opinion and commentary, case reports and extended reports. The manuscript management system is completely online and includes a very quick and fair peer-review system, which is all easy to use. Visit http://www.dovepress.com/testimonials.php to read real quotes from published authors. 